\title{
Intron Splice Region Mutation
}

National Cancer Institute

\section{Source}

National Cancer Institute. Intron Splice Region Mutation. NCI Thesaurus. Code C63428.

Any intronic mutation that occurs at a distance up to 10 bases from the exon junction. 